\title{
COMPARISON OF FRESH AND HARDENED PROPERTIES OF NORMAL, SELF COMPACTING AND SMART DYNAMIC CONCRETE
}

\author{
A. Arun Kumar ${ }^{1 *}$, Raguraam $\mathrm{S}^{2}$ \\ ${ }^{1}$ Civil and Structural Engineering, School of Mechanical and Building Sciences, VIT University, \\ Chennai Campus, Chennai 600127, Tamil Nadu, India \\ ${ }^{2}$ School of Mechanical and Building Sciences, VIT University, Chennai Campus, Chennai 600127, \\ Tamil Nadu, India
}

(Received: July 2017 / Revised: January 2018 / Accepted: April 2018)

\begin{abstract}
This work investigates the fresh, mechanical and durability properties of normal, SelfCompacting Concrete (SCC) and Smart Dynamic Concrete (SDC), which are a new generation of concrete with a lower amount of cementitious content. SDC is a low-fine, self-compacting concrete, that combines the benefits of normal concrete (stability) and self-compacting concrete (fresh properties). Fresh properties such as slump flow, L-box and V-funnel tests were investigated to evaluate its self-compacting properties. Mechanical properties such as compressive, splitting tensile and flexural strengths were also examined to compare its effectiveness with normal concrete. In addition to the fresh and hardened properties, the rapid chloride permeability test was also conducted to check the durability of normal, SCC and SDC concrete mixtures. The test results of the fresh properties clearly showed that SDC exhibited superior flowability in the slump flow, L-box and V-funnel tests within the limits of EFNARC (The European Federation of Specialist Construction Chemical and Concrete Systems) guidelines. The mechanical properties of SDC attained higher compressive strength, splitting tensile strength and flexural strength compared with the normal and SCC concrete mixtures. The rapid chloride permeability tests result of SDC clearly showed that SDC exhibited similar and better results than that of normal and SCC concrete mixtures.
\end{abstract}

Keywords: Durability; Flow properties; Self-compacting concrete; Smart-dynamic concrete; Strength

\section{INTRODUCTION}

Smart dynamic concrete (SDC) is a low-fine Self-Compacting Concrete (SCC) designed to accomplish self-compacting properties with a low amount of cementitious material. The low cementitious concrete with 340 to $390 \mathrm{~kg} / \mathrm{m}^{3}$ of the binder has become a reality for the lower grades of SCC. SDC can be deposited and compacted under its self-weight disregards any vibrational effort, thoroughly fills formworks and even accesses narrow gaps between reinforcement bars. Obtaining concrete without vibration is a challenge to the construction industry. To attain this condition, fresh concrete needs to have both high fluidity and good cohesiveness. In SCC, the flow properties are shown to be efficient through the use of melamine or naphthalene-based superplasticizers with a comparatively high content of cementitious materials (Corinaldesi et al., 2003). SCC plays prominent role in the precast

\footnotetext{
*Corresponding author's email: salem.arun@gmail.com, Tel. +91 443993 1516, Fax. +91 4439932555 Permalink/DOI: https://doi.org/10.14716/ijtech.v9i4.566
} 
industry, as more than half of the concrete used for structural precast elements is SCC. SCC is mainly characterised by a high content of fine aggregate, usually in the range of 450 to 600 $\mathrm{kg} / \mathrm{m}^{3}$, and a low volume of coarse aggregates. This high content of fines along with a high mass of cement paste is needed to supply the appropriate cohesion to prevent bleeding and/or segregation (Jaffer et al., 2010). The content of fines is usually higher than $500 \mathrm{~kg} / \mathrm{m}^{3}$ is characterised by high plastic viscosity and is mostly suitable for heavily reinforced structures.

SCC is unable to replace everyday concrete because of some issues, such as overdesign and high cementitious content, which has the disadvantages of high shrinkage and high cost. To reduce the usage of a high amount of cementitious content and fine aggregates, SDC was introduced. SDC combines the benefits of the normal concrete and self-compacting properties of SCC. Fresh properties include ease of production with adequate robustness in a cost-effective manner. Stability and robustness levels are achieved in SDC using the inventive superplasticizer in contempt of the lesser cement content without the risk of high bleeding and segregation. SDC creates the balance between stability and fluidity of the concrete considering the sensitivity of the mixture. SDC is a smart technology that facilitates the production and develops the application of highly flowable concrete to everyday concrete. Minimisation of the total fine aggregates gives rise to the cutting back of the unit cost of concrete in comparison with normal, SCC and Ready Mix Concrete (RMC) in an eco-friendly manner. Concurrently, the required fresh properties are preserved, so that SCC can be turned into everyday concrete. These properties are achieved without losing the plastic and ultimate properties of concrete through SDC.

\section{REVIEW OF LITERATURE}

The literature review for this study focuses on SCC with ground granulated blast furnace slag (GGBS). The fresh and hardened properties of SCC with GGBS are explained through previous investigations.

Through an experimental investigated on SCC with GGBS as cement replacement. Dinakar et al. (2013) concluded that self-compacting GGBS concrete attained a higher compressive strength of $90 \mathrm{MPa}$ at 28 days and $100 \mathrm{MPa}$ at 90 days. Boukendakdji et al. (2012) explained the effect of two super plasticizers on the self-compacting properties of concrete with $10 \%$, $15 \%, 20 \%$, and $25 \%$ of GGBS, respectively. The test results showed that the polycarboxylate based admixture exhibited superior workability and higher compressive strength than normal concrete. Vejmelková et al. (2011) investigated the rheological, mechanical and durability properties of SCC with GGBS and metakaolin. The test results showed that the fresh property of SCC with GGBS showed high viscosity. Turu'allo (2015) found that higher replacement levels of GGBS increased the activation energy that resulted in the higher compressive strength. Beycioğlu and Aruntaş (2014) studied the workability and mechanical properties of SCC with low lime fly ash, GGBS and micronized calcite (MC). Their study concluded that the mineral admixtures enhanced the slump flow, passing ability and viscosity of SCC. Yehia et al. (2014) evaluated the physical properties of aggregates on the development of strength. In this study the aggregates from three different parts of the United Arab Emirates were used in SCC for strength and durability. The test results revealed that the aggregate from the different sources attained both fresh and properties for the structural applications. Chandwani et al. (2015) found through artificial neural network mechanism about the relationship between cement, fly ash, aggregates, water and admixtures that improved the workability of the fresh concrete in ready mix concrete plant.

As indicated in the literature review on the effect of GGBS on the fresh properties of concrete, the replacement of cement with GGBS not only reduced the cement content but also enhanced 
the fresh properties of SCC. Similarly, for the SDC, previous studies involved few experimental investigations and case studies highlighting the necessity of SDC over SCC in RMC.

Kar et al. (2009) reduced the high cementitious content and fines in SCC to attain the designed strength with flowability, viscosity and passing ability without segregation in SDC. The experimental study involved number of trail studies to reduce the cementitious content. The test results showed that with less cement or high supplementary cementitious materials could improve the strength and durability by using innovative modifying admixtures in SDC. Jaffer et al. (2010) explained a novel approach to design SDC with a cementitious content less than 380 $\mathrm{kg} / \mathrm{m}^{3}$ with an innovative viscosity modifying admixture called RheoMATRIX to achieve the fresh properties of SCC. The test results revealed that SDC could be used as everyday concrete. Through a case study across Asia pacific, namely, in Malaysia, Singapore, Indonesia and China, Huat et al. (2011) found that SDC with a new viscosity modifying agent (polycarboxylate ether) could reduce cementitious and fine aggregate content. The projects in Asia Pacific demonstrated the advantages of SDC about its ease of placement of fresh concrete in to reinforced cement concrete structures at less cost and provided the benefits of SCC with low cementitious content. D'Souza and Yamamiya (2013) explained the application of SDC in the Asian market and concluded that self-compacting properties could be attained with a low amount of cementitious material without detrimental effects. The literature review based on the experimental investigations and the actual application of SDC in Asian countries by BASF Construction Chemicals Asia Pacific, Singapore, shows a clear evidence of the benefits of SDC over SCC.

\section{EXPERIMENTAL PROGRAM}

The experimental investigation involved the comparative analysis of the fresh and hardened properties of normal, SCC and SDC. The fresh properties such as slump flow, L-box and Vfunnel tests were investigated based on the EFNARC guidelines (2002). The mechanical properties such as compressive strength, splitting tensile strength, and flexural strength were evaluated in accordance with IS 516 (2004) and IS 5816 (2004).

The SCC and SDC mixtures were replaced with $30 \%$ GGBS for cement. The concrete mixture proportions were fixed according to the number of trials to achieve the fresh properties of SCC with 30\% GGBS. The normal concrete mixture was designed based on IS 10262 (2009) for $50 \mathrm{MPa}$. The water-binder ratio was fixed for the normal, SCC and SDC mixtures by varying the dosage of high-range water reducing admixtures (polycarboxylate ether-based) to achieve the fresh properties of SCC. The tests for fresh properties, such as slump flow, L-box and Vfunnel were conducted for SCC and SDC. The rapid chloride ion penetration test was also performed to check the durability of the normal, SCC and SDC concrete mixtures.

\section{MATERIAL AND TESTING PROGRAM}

Ordinary Portland cement (OPC) of grade 53 was used based on IS 12269 (2013) as a cementitious material. Locally available fine (passing through $2.36 \mathrm{~mm}$ ) and coarse aggregates of sizes $20 \mathrm{~mm}$ and 12mm were used based on IS 383 (2002). Potable tap water was used for both mixing and curing of concrete. A high-range water reducing admixture conforming to IS 9103 (1999) was used for maintaining the fresh properties of SCC. Table 1 shows the physical properties of cement, and GGBS. The concrete mixture proportions are presented in Table 2. 
Table 1 Physical properties of cement and GGBS

\begin{tabular}{lc}
\hline \multicolumn{1}{c}{ Properties } & Value \\
\hline Specific gravity of cement & 3.15 \\
Specific gravity of GGBS & 2.9 \\
Initial setting time of cement (minutes) & 90 \\
Final setting time of cement (minutes) & 330 \\
Consistency & $31 \%$ \\
\hline
\end{tabular}

Table 2 Mixture proportions $\left(\mathrm{kg} / \mathrm{m}^{3}\right)$

\begin{tabular}{lcccccc}
\hline Mixture & Cement & GGBS & $\begin{array}{c}\text { Fine } \\
\text { aggregate }\end{array}$ & $\begin{array}{c}\text { Coarse } \\
\text { aggregate }\end{array}$ & $\begin{array}{c}\text { W/B } \\
\text { Ratio }\end{array}$ & $\begin{array}{c}\text { HRWRA } \\
\text { in \% }\end{array}$ \\
\hline Normal & 389 & 0 & 715 & 1278 & 0.4 & 0.5 \\
SCC & 297.5 & 127.5 & 883 & 957 & 0.4 & 3.5 \\
SDC & 272.3 & 116.7 & 960 & 840 & 0.4 & 4.5 \\
\hline
\end{tabular}

\section{RESULTS AND DISCUSSION}

The fresh property of the SCC mixture is the most important property to measure the flowability and passing ability of concrete in its fresh state. The fresh property tests were performed to check the flowability of the concrete. The dry mixture was allowed to be mixed in the concrete rotary mixture machine to maintain its homogeneity. The high-range water reducing admixture was mixed with water and added to the dry mixture. The fresh concrete was then tested for slump flow, Vfunnel and L-box tests. The test results of the fresh properties are given in Table 3.

Table 3 Test results of the fresh properties

\begin{tabular}{|c|c|c|c|c|}
\hline \multirow{2}{*}{ Mixture } & \multicolumn{2}{|c|}{ Slump flow } & \multirow{2}{*}{$\begin{array}{c}\text { V funnel } \\
\text { (s) }\end{array}$} & \multirow{2}{*}{$\begin{array}{c}\text { L-box } \\
\text { Ratio }\end{array}$} \\
\hline & $\operatorname{Max}(\mathrm{mm})$ & T50 (s) & & \\
\hline $\begin{array}{l}\text { EFNARC } \\
\text { (guidelines) }\end{array}$ & $600-800$ & $2-5$ & $6-12$ & $0.8^{-1.0}$ \\
\hline SCC & 602 & 2.19 & 9.73 & 0.84 \\
\hline SDC & 634 & 1.45 & 7.27 & 0.93 \\
\hline
\end{tabular}

The fresh property of SCC attained within the range of the EFNARC guidelines by increasing the dosage of HRWRA from $0.50 \%$ to $3.5 \%$, whereas for SDC the dosage of HRWRA was $28 \%$ higher than that of the SCC concrete mixture. The slump flow of $602 \mathrm{~mm}$ was obtained for the SCC mixture as shown in Figure 1. Similarly, the slump flow of SDC of $634 \mathrm{~mm}$ was attained in $1.45 \mathrm{~s}$ without segregation in SDC mixture as shown in the Figure 2. 


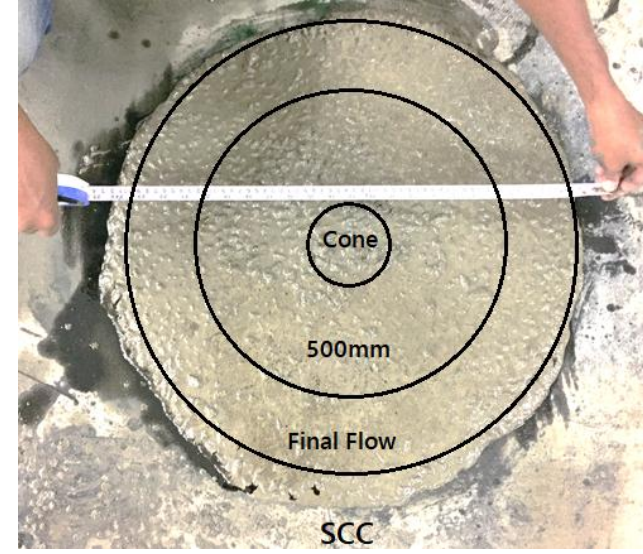

Figure 1 Slump flow of SCC

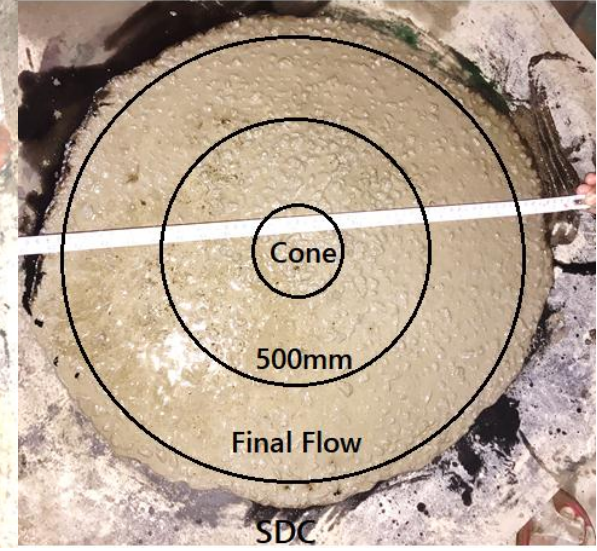

Figure 2 Slump flow of SDC

Similarly, the V-funnel and L-box tests results revealed that increasing the dosage of HRWRA enhanced the fresh properties of SDC. The HRWRA extends the role of the viscosity-modifying agent that settles and disperse the cementitious and fine aggregate content without bleeding. Evidently, SDC exhibited better flow and passing ability than SCC with less cementitious content.

\subsection{Mechanical Properties}

The mechanical properties, such as compressive strength, splitting tensile strength and flexural strength were tested. The test results are presented in Table 4 . The compressive strength of the normal, SCC and SDC mixtures were tested at 7, 28, and 56 days, respectively. The compressive strength test and splitting tensile strength were tested in accordance to IS: 5816 (1970). The control concrete attained compressive strength of $34 \mathrm{MPa}, 57 \mathrm{MPa}$, and $58 \mathrm{MPa}$ at 7, 28, and 56 days, respectively. The SCC attained similar compressive strength in comparison with the normal concrete, the SDC mixture exhibited higher compressive strength than the normal and SCC mixtures similar to their fresh properties.

Table 4 Strength of concrete $(\mathrm{MPa})$

\begin{tabular}{lccccc}
\hline \multirow{2}{*}{ Mixture } & \multicolumn{2}{c}{ Compressive Strength } & $\begin{array}{c}\text { Flexural } \\
\text { strength }\end{array}$ & $\begin{array}{c}\text { Splitting } \\
\text { tensile } \\
\text { strength }\end{array}$ \\
\cline { 2 - 6 } & 7 days & 28 days & 56 days & 28 days & 28 days \\
\hline Normal & 34.26 & 57.60 & 58.25 & 4.90 & 4.33 \\
SCC & 32.85 & 56.34 & 58.62 & 5.05 & 4.24 \\
SDC & 33.80 & 58.18 & 59.14 & 5.26 & 4.36 \\
\hline
\end{tabular}

The higher compressive strength of SDC was due to the replacement of cement with $30 \%$ GGBS and the increase in the dosage of HRWRA. A similar behaviour was observed in SDC in flexural and splitting tensile strength at 28 days respectively.

The flexural strength of SCC was $3 \%$ higher than that of normal concrete at 28 days. At 28 days, SDC attained flexural strength of 5.26 MPa which was $7 \%$ higher than that of normal concrete and $4 \%$ higher than the SCC mixture. The splitting tensile strength of the control and SCC mixtures was 4.33 MPa and 4.24 MPa at 28 days, respectively. The SDC mixture obtained similar splitting tensile strength in comparison with normal concrete. The higher strengths of SCC and SDC concrete mixtures were due to the decrease in the water-binder ratio by 
increasing the dosage of the high-range water-reducing admixture. The high-range water reducing admixture played a similar role of increasing the workability and strength.

\subsection{Rapid Chloride Ion Penetration Test}

The durability of the normal, SCC and SDC concrete samples were tested by rapid chloride ion penetration test in accordance with ASTM C 1202-10. The rapid chloride ion penetration test was performed for 28 days and the results are shown in Figure 3.

The test results of rapid chloride ion penetration test at 28 days showed that normal concrete exhibited low chloride ion penetration due to less aggregate and cement ratio with $0.5 \%$ of HRWRA. Similarly, SCC and SDC concrete samples exhibited very low chloride ion penetration with $3.5 \%$ and $4.5 \%$ of HRWRA, respectively. The binder (cement and GGBS) to aggregates content, water to binder ratio and the dosage of HRWRA not only played a vital role in fresh properties but also enhanced the resistance against chloride ion penetration. The HRWRA increased the flow through the process of dispersion of the binder (cement and GGBS) with the aggregates. This mechanism created a dense packing of the matrix and created resistance against chloride ion penetration.

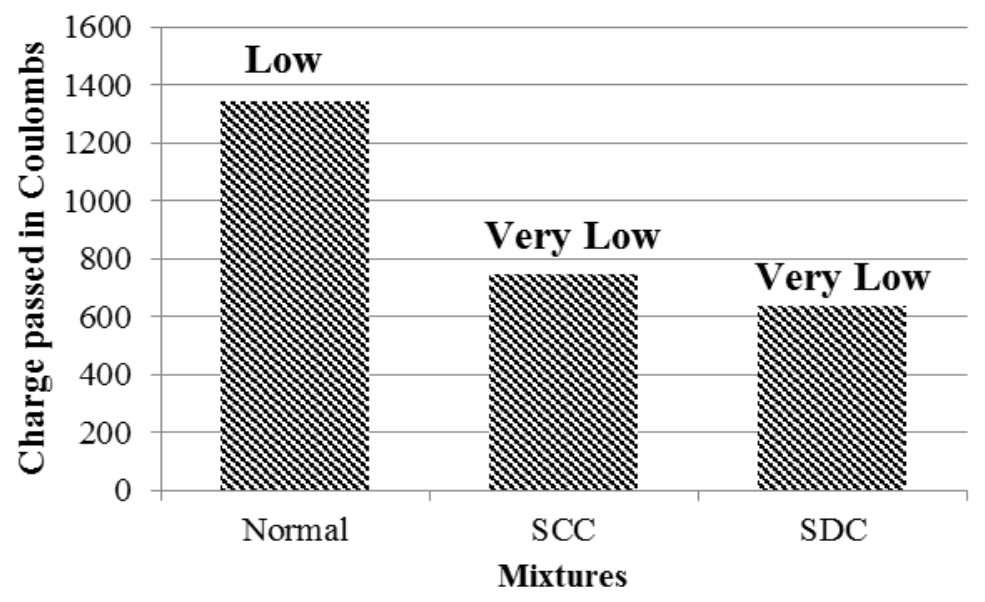

Figure 3 Rapid Chloride ion penetration test

\section{CONCLUSION}

The following conclusions are drawn from the experimental study of SDC for fresh and hardened properties: (1) SDC with a low cementitious content can produce better flow properties than SCC with the incorporation of HRWRA; (2) The fresh properties of SDC exhibited superior performance in the slump flow, V-funnel and L-box tests. The improved fresh property was due to the HRWRA and mixture proportion (fine to coarse aggregates ratio); (3) The compressive strength of SDC was similar and higher at 28 days and 56 days compared to normal concrete; (4) The splitting tensile strength of normal concrete and SDC were similar; (5) The flexural strength of SDC showed an increase of 7\% compared with normal concrete; (6) The durability property of SCC and SDC was similar in comparison with their fresh and mechanical properties. SCC and SDC exhibited very low chloride ion penetration in comparison with that of normal concrete; (7) SDC obtained similar and better results than normal concrete. SDC featured the advantage of both SCC (flow property) and normal concrete (strength and reduction in cement content). 


\section{ACKNOWLEDGEMENT}

The author would like to thank VIT University Chennai Campus for providing the facilities to conduct this study. The author acknowledges BASF Chemicals, Chennai for providing the chemical admixture used in this research.

\section{REFERENCES}

American Society for Testing and Materials (ASTM), 2010. Standard Test Method for Electrical Indication of Concrete's Ability to Resist Chloride Ion Penetration. ASTM C1202-10, Philadelphia, USA

Beycioğlu, A., Aruntaş, H.Y., 2014. Workability and Mechanical Properties of Self-compacting Concretes Containing LLFA, GBFS and MC. Construction and Building Materials, Volume 73, pp. 626-635

Boukendakdji, O., Kadri, E.-H., Kenai, S., 2012. Effects of Granulated Blast Furnace Slag and Superplasticizer Type on the Fresh Properties and compressive Strength of Selfcompacting Concrete. Cement Concrete and Composites, Volume 34(4), pp.583-590

Chandwani, V., Agrawal, V., Nagar, R., Singh, S., 2015. Modeling Slump of Ready Mix Concrete using Artificial Neural Network. International Journal of Technology. Volume 6(2), pp. 207-216

Corinaldesi, M., Khurana, R., Magarotto, R., Roncero, J., 2003. Low Fines Content SelfCompacting Concrete. BASF, Italy

D'Souza, B., Yamamiya, H., 2013. Applications of Smart Dynamic Concrete. In: Third International Conference on Sustainable Construction Materials and Technologies set for Kyoto. Japan

Dinakar, P., Sethy, K.P., Sahoo, U.C., 2013. Design of Self-compacting Concrete with Ground Granulated Blast Furnace Slag. Materials and Design, Volume 43, pp. 61-169

EFNARC (European Federation of National Trade Associations Representing Producers and Applicators of Specialist Building Products), 2002. Specification and Guidelines for Selfcompacting Concrete. Hampshire, UK

Huat, S.K., Kar, N., Qiuling, F., 2011. The Asian Experience in Low Fines Self Consolidating Concrete (SCC) in Everyday Applications. In: $36^{\text {th }}$ Conference on Our World in Concrete and Structures, Singapore

IS (Indian Standard), 2002. Specification for Coarse and Fine Aggregates from Natural Sources for Concrete. IS: 383, New Delhi, India

IS (Indian Standard), 2004. Indian Standard Admixtures-Specification. IS: 9013 New Delhi, India

IS (Indian Standard), 2004. Methods of Tests for Concrete. IS: 516, New Delhi, India

IS (Indian Standard), 2004. Splitting Tensile Strength of Concrete - Method of Test. IS: 5816, New Delhi, India

IS (Indian Standard), 2009. Concrete Mix Proportioning-Guidelines. IS: 10262, New Delhi, India

IS (Indian Standard), 2009. Specification for 53 Grade Ordinary Portland Cement. IS: 12269, New Delhi, India

Jaffer, R., Magarotto R., Roncero, J., 2010. Smart Dynamic Concrete: New Approach for the Ready-mixed Industry. Advance Cement Based Materials, Van Zijl and Boshoff (eds)

Kar, N., Hyat, S.K., Kluegge, J., 2009. New Dimension in Self Compacting Concrete (SCC): Smart Dynamic Construction. In: $34^{\text {th }}$ Conference on Our World in Concrete and Structures, Singapore 
Turu'allo, G. 2015. Using ggbs for Partial Cement Replacement in Concrete: Effects of Waterbinder Ratio and ggbs Level on Activation Energy. International Journal of Technology. Volume 6(5), pp. 790-799

Vejmelková, E., Keppert, M., Grzeszczyk, S., Skaliński, B., Černý, R., 2011. Properties of Selfcompacting Concrete Mixtures Containing Metakaolin and Blast Furnace Slag. Construction and Building Materials, Volume 25(3), pp. 1325-1331

Yehia, S., AlHamaydeh, M., Farrag, S., 2014. High-strength Lightweight SCC Matrix with Partial Normal-weight Coarse-aggregate Replacement: Strength and Durability Evaluations. Journal of Materials in Civil Engineering, Volume 26(11), pp.1-11 